\title{
Total Synthesis of the Gilvocarcins
}

\author{
Keisuke Suzuki*, Takashi Matsumoto, and Takamitsu Hosoya \\ Department of Chemistry, \\ Keio University,
}

\begin{abstract}
This account describes our synthesis of the gilvocarcin-class aryl C-glycoside antibiotics. Particular attention has been given to the strategies and tactics developed during the study, which include (1) regio- and stereocontrolled aryl $C$-glycoside formation, and (2) regioselective [4 +2$]$ cycloaddition of 2-methoxyfuran with a sugarbearing benzyne. A new method for the efficient generation of benzyne species at low temperature is also discussed.
\end{abstract}

\section{Introduction}

Aryl $C$-glycoside antibiotics constitute an emerging class of bioactive natural products, possessing a characteristic aromatic-carbohydrate hybrid structure as exemplified by compounds 1-4 (Figure 1). They exhibit a wide variety of biological activities, such as antibacterial, antitumor, and enzyme inhibitory effects, and are currently attracting considerable synthetic interests (ref. 1).

The gilvocarcins belong to such a class of natural products, and their structures are characterized by the $C$-glycosylated benzonaphthopyranone skeleton. Among these, gilvocarcin V (3) has been attracting considerable attention due to the high antitumor activity with exceptionally low toxicity. At this juncture it would be appropriate to introduce the general aspects of aryl $C$-glycoside chemistry as well as our own background prior to commencing our synthetic work on the gilvocarcins.

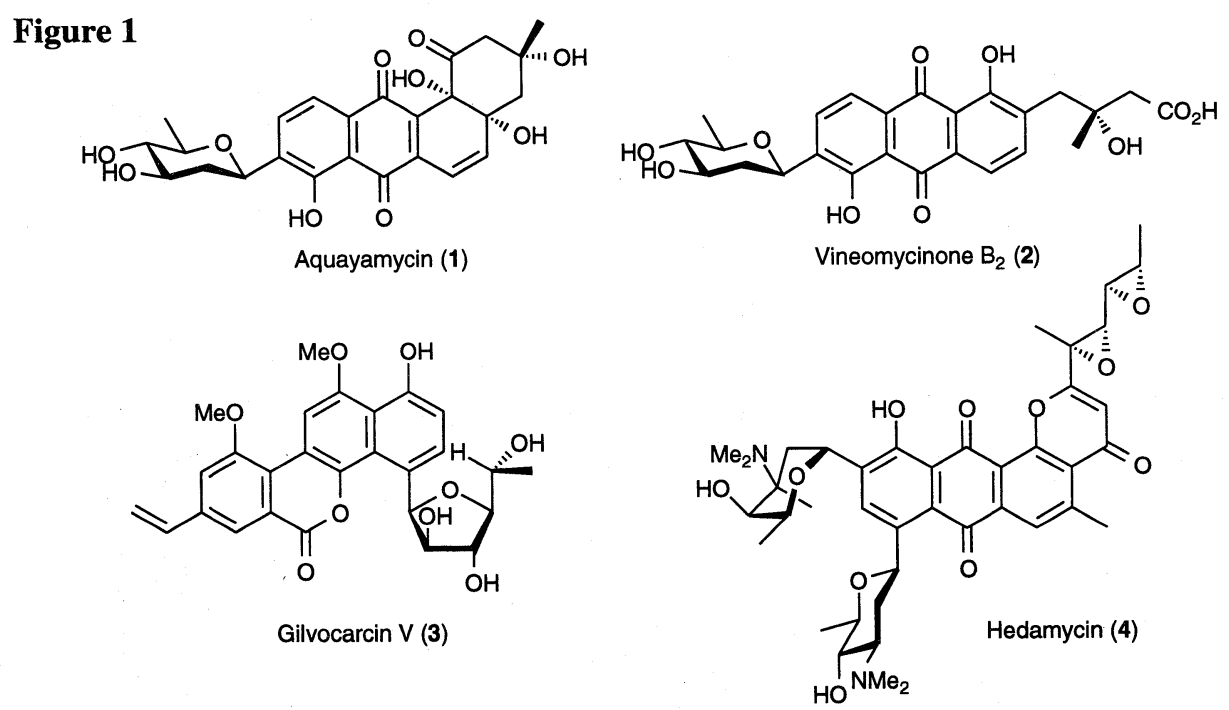




\section{Biosynthetic Implications and Biomimetic Synthetic Approaches}

The biosynthesis of this class of compounds has two distinct possibilities in terms of sequence of aryl $C$-glycoside bond formation. In other words, does it occur before or after the aromatization of the polyketide biosynthetic intermediates (path A or B, Scheme 1)?

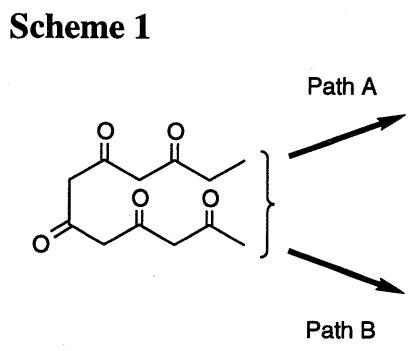<smiles>O=C1C2=C(CCCC2)C(=O)c2c(O)cccc21</smiles>

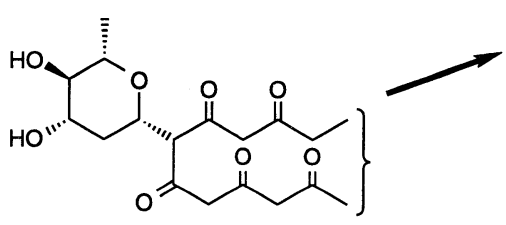<smiles>C[C@@H]1O[C@H](c2ccc3c(c2O)C(=O)C(CC2CC4CCC2CC4=O)=C3)C[C@@H](O)[C@@H]1O</smiles>

Along these lines, several biomimetic synthetic approaches to this class of compounds have been reported. Eq. 1 illustrates Danishefsky's pioneering attempt to synthesize gilvocarcin $\mathrm{V}$ by introducing a glycoside progenitor to a fully elaborated aromatic (ref. 2a). The chromophore, defucogilvocarcin, is also a natural product (ref. $2 \mathrm{~b}$ ). On the other hand, eq. 2 shows Yamaguchi's approach via the $C$-glycosylation of $\beta$-keto ester followed by biomimetic construction of the aromatic moiety, which has culminated in the first total synthesis of urdamycinone $\mathrm{B}$, an aglycon of the angucycline-type aryl $C$-glycoside (ref. 3).<smiles>C=Cc1cc(OC)c2c(c1)c(=O)oc1cccc(OC)c12</smiles>

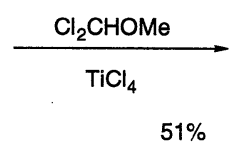<smiles>C=Cc1cc(OC)c2c(c1)c(=O)oc1c(C)ccc(OC)c12</smiles><smiles>C[C@H]1O[C@H](O)C[C@H](O)[C@@H]1O</smiles><smiles>CCOCC(=O)CC(=O)OCC</smiles><smiles>CCC(=O)NC(=O)O</smiles><smiles>CCOCC(=O)C(C(=O)OCC)[C@H]1C[C@H](O)[C@@H](O)[C@H](C)O1</smiles>

\section{Our Own Background before 1990}

Since the late 1980s', we have been interested in the synthesis of these fascinating natural products. The synthetic approaches to these new natural products were largely unexplored at that time. In the formation of aryl $C$-glycoside linkage, one must consider following two issues pertaining to selectivity. (1) The regioselectivity of the aromatic substitution. As seen in Figure 1, the aryl $C$ glycosidic bonds are often located ortho to a phenolic hydroxyl group. However, other patterns of $C$ glycoside substitution are also possible as in the case of the gilvocarcins, the present target (vide infra). (2) The stereoselectivity of the anomeric center. The anomeric effect is not a dominant stereoelectronic factor in aryl $C$-glycosides, and they are better viewed as tetrahydropyrans/furans possessing a large $\mathrm{C}(1)$ substituent, i.e., the aryl group.

3.1. A Gift from a Natural Product. Figure 2 shows the structure of a natural product named benzanthrin B (5), in which the same sugar is doubly installed at adjacent positions, one as $O$ glycoside and the other as $C$-glycoside (ref. 4). It occurred to us that the biosynthesis of such 
compounds may proceed via the initial $O$-glycosidation followed by migration of the glycoside residue to form the $C$-glycoside. Such a putative idea led us to find that the equivalent strategy in chemical synthetic term is feasible and has general application. Thus, we developed a new reaction for the selective formation of aryl $C$-glycoside linkages, which we call trivially, as the reaction pathway suggests, the $O \rightarrow C$-glycoside rearrangement, as outlined in 3.2 (ref. 5).
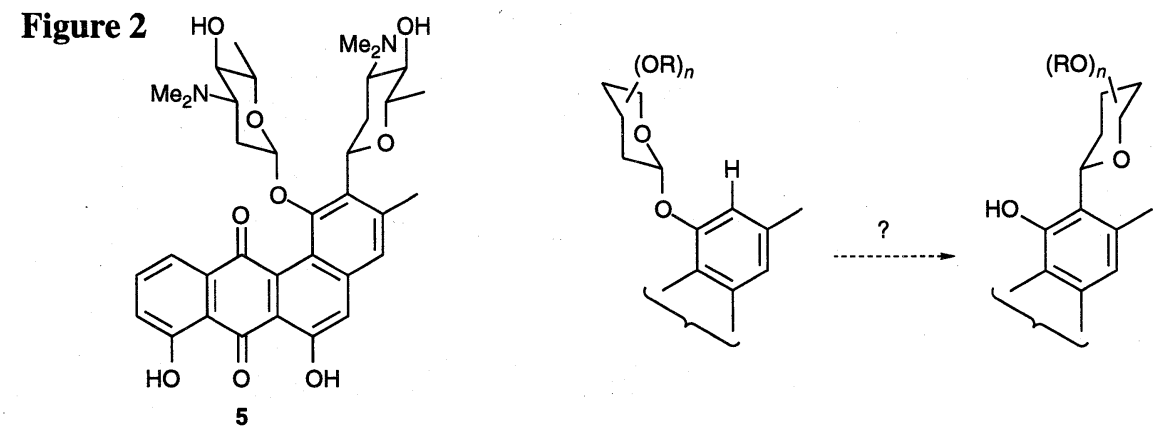

\section{2. $O \rightarrow C$-Glycoside Rearrangement (ref. 5)}

3.2.1. General Reaction Profiles. In practice, a mixture of phenol 7 and glycosyl donor 6 is treated with Lewis acid at low temperature, typically at $-78{ }^{\circ} \mathrm{C}$, thereby forming $O$-glycoside 8 . As phenols are highly reactive in such occasions, only a rather weak Lewis acid is sufficient for this first step, and a variety of glycosyl donors, ranging from the reactive $(X=F)$ to the less reactive $(X=O A c)$, can be utilized (ref. 5c). The next step, conversion of 8 to the corresponding $C$-glycoside 9, proceeds while the reaction temperature is gradually raised, typically, to $0{ }^{\circ} \mathrm{C}$. This conversion proceeds most probably via an oxonium-phenolate ion pair $\mathbf{A}$, generated by complexation of a Lewis acid to the exocyclic oxygen in 8 . This ionization could be reversible, but the trapping at the aromatic carbon leads to the irreversible formation of $C$-glycoside 9. Hence this process could be viewed as a FriedelCrafts or aromatic aldol reaction of the ion pair, $\mathbf{A}$. below.

There are two notable characteristic features in this aryl $C$-glycosidation, which are discussed

Scheme $2 O \rightarrow C$-Glycoside Rearrangement

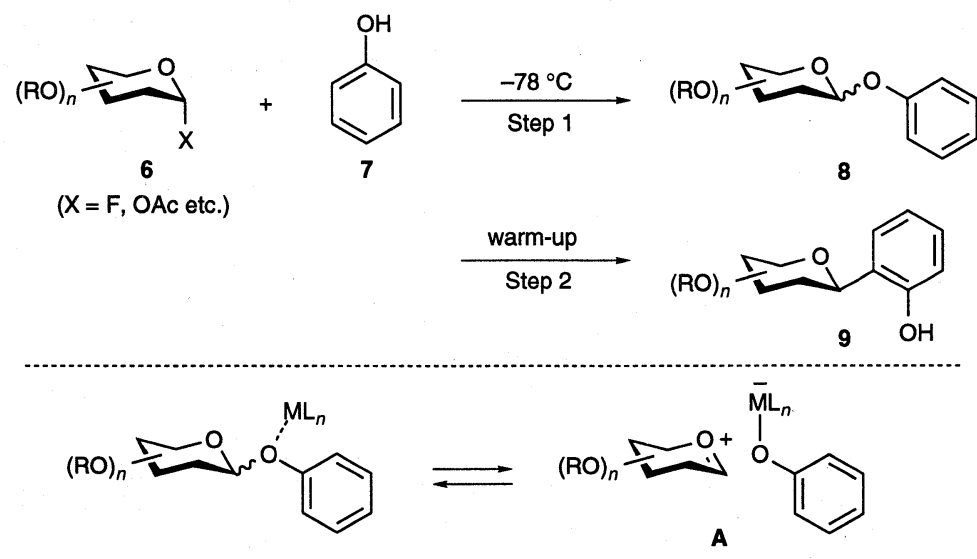

3.2.2. The Third Step. The reaction sequence involves an additional step, that is, the Lewis acid promoted in situ-anomerization of the $C$-glycoside product. The Lewis acid activates the endocylic oxygen in 9 to generate a quinone methide species $\mathbf{B}$, and its ring opening-reclosure sequence drives the system towards thermodynamic control. Notice that the anomeric effect is not 
significant. In case aryl $C$-pyranosides are concerned, the equatorial disposition of the $\mathrm{C}(1)$-aryl group is favored, and the transition from $\alpha$ to $\beta$ occurs if an equilibration pathway is opened by a Lewis acid with suitable level of complexation ability. It should be noted that the coordination effect is responsible, at least partly, for determining the equilibrium point. Such an effect becomes prominent in the case of aryl $C$-furanoside, for example, where the $\alpha / \beta$ preference is not obvious (see 5.1).

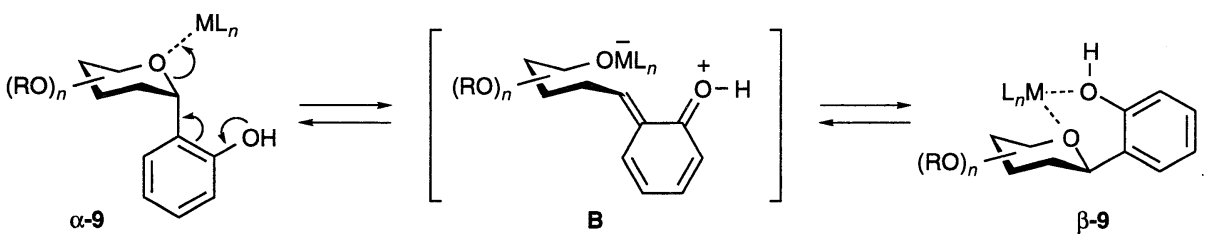

3.2.3. The Ortho Selectivity. Another key feature in this reaction is the regioselectivity: The aryl $C$-glycoside formation occurs at the ortho position to a phenol. Thus, the free phenol in the substrate serves as a directing group for site selective formation of the aryl $C$-glycoside linkages. Taking advantage of this particular aspect, we have succeeded in the total synthesis of vineomycinone $\mathrm{B}_{2}$, which can actually be viewed as a synthetic cornerstone in this area (refs. 5b,e,6). More recently, we have succeeded in the first total synthesis of a $C$-glycosylated angucycline antibiotic, C104 (10) (ref. 7).

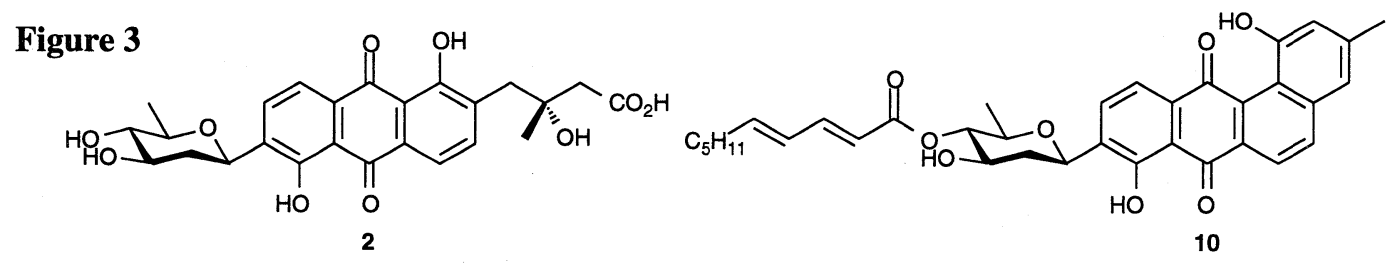

\section{Synthetic Plan and Model Studies}

4.1. Structures of the Gilvocarcins (ref. 8). Figure 4 shows the gilvocarcin class antitumor antibiotics, which share a densely functionalized tetracyclic skeleton armed with various rare sugars at the $\mathrm{C}(4)$ position (ref. 8). Among the additional variation in the $\mathrm{C}(8)$ substituent, the vinyl group is suggested to be essential to the biological activities (ref. 9). Thus, gilvocarcin $\mathrm{V}$, that shows strong antitumor activity with very low toxicity, has attracted considerable attention to its total synthesis. Although there are over ten examples for the synthesis of the aromatic portion, defucogilvocarcin, there were no accomplishments of synthesizing the glycosylated full structure (ref. 1c).

Figure 4<smiles></smiles>
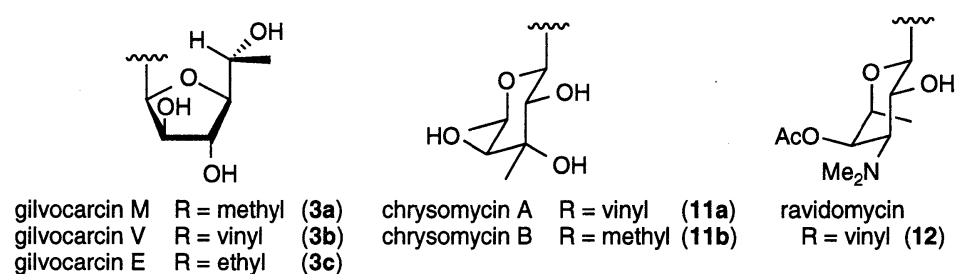

The gilvocarcins are unique among the aryl $C$-glycoside antibiotics in that the $C$-glycoside bond is located at the position para to a phenolic hydroxyl. This was an obvious obstacle to the adoption of the $O \rightarrow C$-glycoside rearrangement, and we set out to solve this problem at the initial stage of our synthetic venture. 
4.2. Resorcinol Trick (ref. 5d). Our approach to the problem is shown in Figure 5, which relies on the fact that the "ortho selectivity" of $O \rightarrow C$-rearrangement holds for mono-protected resorcinol 13 which in turn delivers $C$-glycoside 14 with an additional oxygen functionality at the para position. Triflate 15, derived from $C$-glycoside 14, then serves as a versatile precursor for various aryl $C$-glycosides. Hydrogenolysis gives the deoxygenated product 16 that has a paraoxygen function. Stille coupling of $\mathbf{1 5}$ with organotin reagents enables the preparation of elaborated aryl $C$-glycosides, such as $\mathbf{1 7}$ and $\mathbf{1 8 .}$

\section{Figure 5}

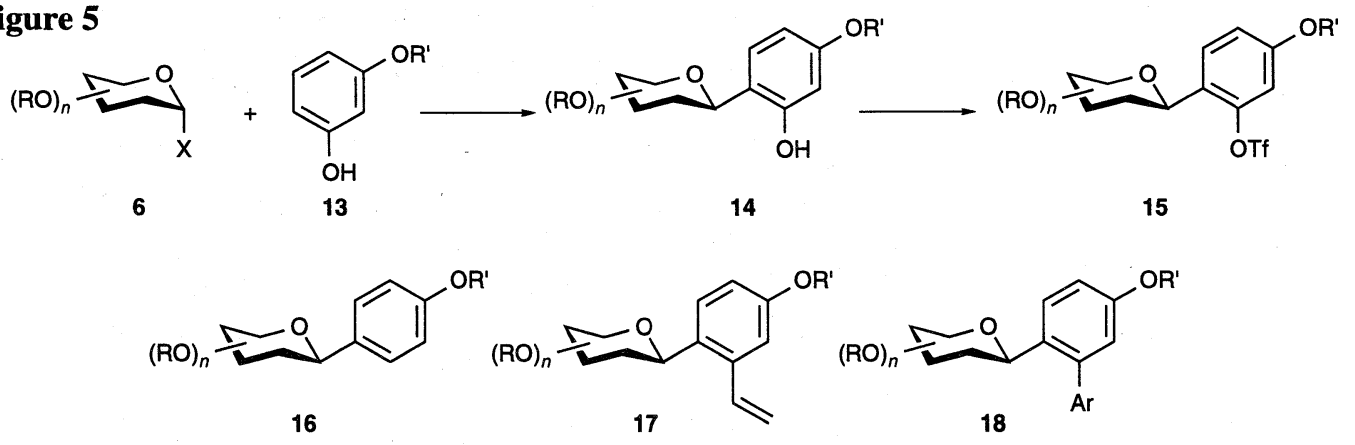

4.3. Retrosynthesis and Two Additional Issues Foreseen (ref. 10). Scheme 3 shows our retrosynthetic analysis (Note the target structure in this scheme is enantiomeric to the natural product that was later clarified by the completion of our total synthesis, ref. 10). The first disconnection was done at the biaryl bond (Step A). Several methods had been already reported for this particular bond formation, among which the ingenious method of Martin (ref. 11) attracted us by the relevance to our synthetic plan.

So the problem was focused on a sugar-bearing naphthalenetriol derivative 19, in which three hydroxyl groups on the naphthalene ring are differentially protected. Preliminary studies had shown that the access to 19 via direct introduction of a sugar to the naphthalenetriol derivative was difficult in terms of the regioselectivity. Thus, for further simplifying the aromatic portion, a two-bond disconnection was considered (Step B), hoping that the benzyne-furan cycloaddition reaction would proceed regioselectively (see 4.4.2). The last, but not least of the problems was the aryl $C$-glycoside formation from the apparently sterically more congested side, 1,2-cis and 1,4-cis (Step C).
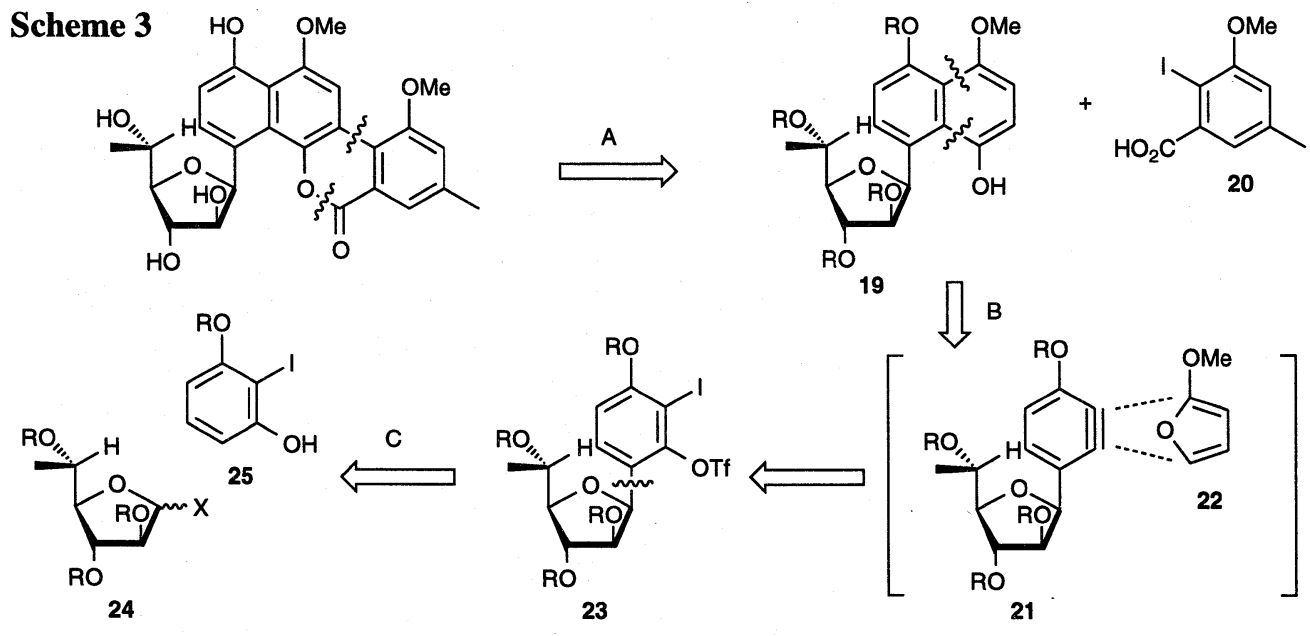

Bearing these problems in mind, we carried out a model study to acquire a grasp of the feasibility of Step B. 
4.4. Naphthalene Annulation. The potential to access the naphthalenetriol derivative (19 in Scheme 3) was examined via the benzyne-furan [2+4] cycloaddition. Although benzyne has long been known in organic synthesis as a reactive species (ref. 12), the scope to use it in practice has been restricted, primarily due to the lack of a truly effective method for its generation.

4.4.1. New Generation Method of Benzynes (ref. 13a). We initially focused on the baseinduced elimination from aryl triflate, which, however, proved to be unyielding. Although a strong base, e.g. LDA or $n$-BuLi, does generate benzyne from 26, the rate of proton abstraction is slow in comparison to the elimination, so that the benzyne once generated reacts with the remaining base (eq. 4). At this stage, we reasoned that the halogen-lithium exchange, an extremely fast reaction even at $-100{ }^{\circ} \mathrm{C}$, would match the super leaving group ability of triflate and thus give rise to the effective benzyne generation at low temperature. Experimentally, this was found to be the case as exemplified in eq. 5. Upon treatment of 27 with $n$-BuLi at $-78^{\circ} \mathrm{C}$, benzyne was rapidly generated and trapped by 28 to give cycloadduct 29 in $90 \%$ yield. It is also noteworthy that the use of the triflate is essential, as the corresponding tosylate or mesylate gives far inferior results.

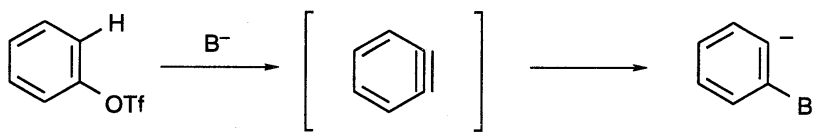

26<smiles>Brc1ccccc1Br</smiles>

27<smiles>c1ccc(-c2oc(-c3ccccc3)c3ccccc23)cc1</smiles>

28

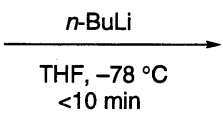

$90 \%$<smiles></smiles>

29

4.4.2. Regioselective Route to Naphthalenetriol Derivatives (ref. 13). In turning our focus to the regioselectivity, our expectation was the following. The LUMO of benzyne is unusually low, so that we consider the frontier orbital interaction between LUMO of the benzyne and HOMO of the furan. As the reacting orbital of benzyne is in the plane of the aromatic ring, orthogonal to the aromatic $\pi$-system, only the inductive effect of the alkoxyl group is relevant. The electron withdrawal makes the LUMO coefficient larger at the distal side, and the primary orbital interaction shown below led us to anticipate that the head-to-head cycloaddition would be favored.

Figure 6<smiles>OCCCCCCc1c(O)cccc1O</smiles>

LUMO

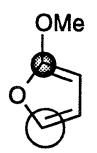

HOMO

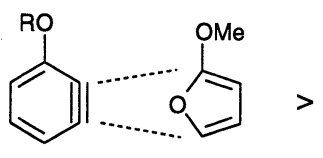

head-to-head<smiles>COc1ccc(C2Cc3c(O)cccc32)o1</smiles>

head-to-tail

To our delight, the reaction of 30 with 2-methoxyfuran (22) went indeed nicely to achieve the head-to-head cycloaddition in high selectivity (eq. 6). The spontaneous aromatization of $\mathbf{3 1}$ provided the desired di-protected naphthalenetriol 32, where the three hydroxyls are nicely differentiated. The selectivity exceeded 10/1.<smiles>Oc1cccc(O)c1I</smiles>

30<smiles>COc1ccco1</smiles>

22

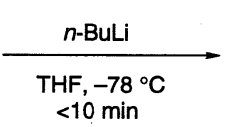<smiles>COc1cccc2c1C1(C=CC2)OCCO1</smiles>

31<smiles>COc1ccc(O)c2c(O)ccc(O)c12</smiles>

$R=M e: 76 \% ; R=$ MOM: $74 \% ; R=B n: 82 \%$ 


\section{Unified Approach to Total Synthesis of the Gilvocarcins (ref. 10)}

5.1. Contrasteric Aryl $\boldsymbol{C}$-Glycoside Bond Formation - the Initial Step. According to the synthetic plan outlined in Scheme 3, we studied the initial $C$-glycoside forming step in detail. Central to this issue was that of stereocontrol, since a requisite $\alpha$-selective $C$-glycosylation seemed unfavorable due to the steric hindrance by two substituents at C-2 and C-4 disposed over to the $\alpha$ side. In addition to such kinetic considerations, a thermodynamic factor should be taken into account as illustrated by Jain's experiment (ref. $8 \mathrm{~g}$ ). Upon acid treatment, gilvocarcin $\mathrm{V}$ undergoes anomerization to give ca. $1 / 1$ mixture of furanoside $\alpha$ - and $\beta$-anomers. The anomerization proceeds most probably via a quinone methide species as discussed before (see 3.2.2), which is strongly supported by the formation of the $C$-pyranoside under these conditions (eq. 7). Thus, the stereocontrolled formation of this aryl $C$-glycoside bond is not a trivial issue, and may be subject to not only kinetic but also thermodynamic control.
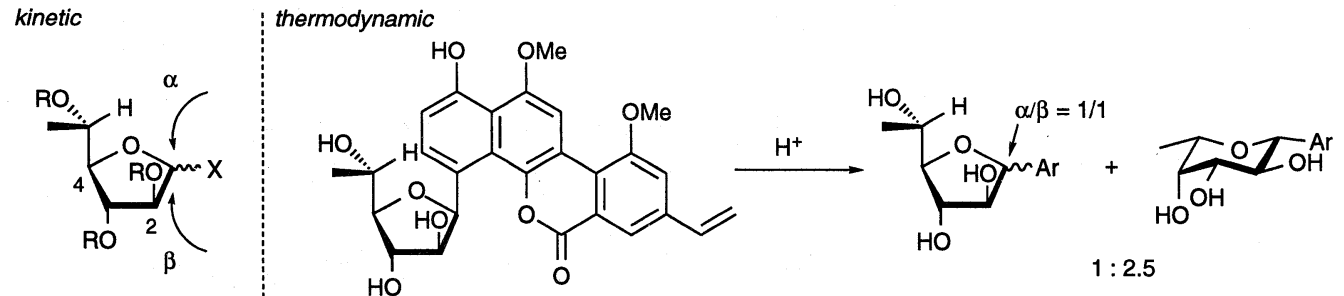

Table 1 shows selected data of the attempted reactions of phenol $\mathbf{3 3}$ and glycosyl acetate 34 . The reactions were carried out by treating 33 and 34 with various Lewis acids at $-78{ }^{\circ} \mathrm{C}$, where the $O$ glycoside rapidly formed, followed by the gradual warming to complete the $O \rightarrow C$-glycoside rearrangement. It turned out that the $\alpha / \beta$ ratios significantly vary depending on the Lewis acid employed as well as the final reaction temperature $\left(\mathrm{T}^{\circ} \mathrm{C}\right) . \quad \mathrm{SnCl}_{4}$ gave 35 slightly rich in the $\alpha$ anomer at the final temperature of $-20^{\circ} \mathrm{C}$ (run 1), whereas $35-\beta$ became dominant at $0{ }^{\circ} \mathrm{C}$ (run 2). Such changeover of the anomeric ratio was even more impressive in the presence of $\mathrm{AgClO}_{4}$, which occurred at lower temperature, leading to an extremely high $\beta$-selectivity at $-20^{\circ} \mathrm{C}$ (runs 3,4 ). In sharp contrast, the cationic hafnocene complex gave the desired $\alpha$-anomer with $8 / 1$ selectivity at -20 ${ }^{\circ} \mathrm{C}$ (run 5), and in this particular case, the anomerization was sluggish to hold a $7 / 1$ level of $\alpha$ selectivity even after warm-up to room temperature (run 6).

Table 1<smiles>Oc1cccc(O)c1I</smiles>

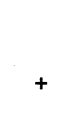

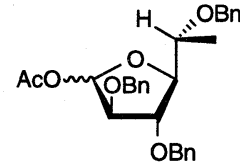

34
33

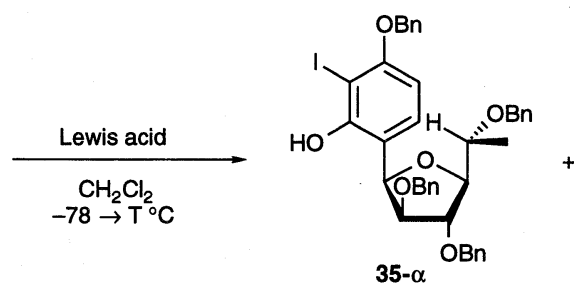

$\alpha / \beta$

\begin{tabular}{clccc}
\hline Run & Lewis acid & $\mathrm{T} /{ }^{\circ} \mathrm{C}$ & Yield $/ \%$ & $\alpha / \beta$ \\
\hline 1 & $\mathrm{SnCl}_{4}$ & -20 & 67 & $2.6 / 1$ \\
2 & $\mathrm{SnCl}_{4}$ & 0 & 75 & $1 / 2.5$ \\
3 & $\mathrm{SnCl}_{4}-\mathrm{AgClO}_{4}$ & -40 & 60 & $5.1 / 1$ \\
4 & $\mathrm{SnCl}_{4}-\mathrm{AgClO}_{4}$ & -20 & 69 & $1 / 58$ \\
5 & $\mathrm{Cp}_{2} \mathrm{HfCl}_{2}-\mathrm{AgClO}_{4}$ & -20 & 86 & $8.2 / 1$ \\
6 & $\mathrm{Cp}_{2} \mathrm{HfCl}_{2}-\mathrm{AgClO}_{4}$ & +25 & 88 & $7 / 1$ \\
\hline
\end{tabular}

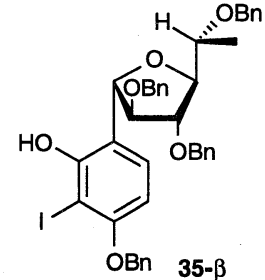


In order to gain some insight into the disparity of the above stereochemical results, we examined the relative thermodynamic preference of $\alpha$ - and $\beta-35$ by carrying out the acid catalyzed anomerization under forcing conditions $\left(10 \% \mathrm{HClO}_{4}, 1,4\right.$-dioxane, $\left.100^{\circ} \mathrm{C}, 8 \mathrm{~h}\right)$. The result was the formation of ca. 1/1 anomeric mixture of 35 starting from either the $\alpha$ or $\beta$ anomer of 35, suggesting that the preference is not far from unity (cf. eq. 7).

Our interpretation of these results is as follows. The anomeric ratio reflects the stability difference of the $\alpha$ - and $\beta$-anomers coordinated to the Lewis acid rather than in their free forms. $\mathrm{SnCl}_{4}-\mathrm{AgClO}_{4}$ not only promotes anomerization via a quinone methide but also contributes to accumulating the $\beta$-anomer by complexation, although the precise coordination chemistry remains unclear. Variation of the metal center, ligands, and the coordination states endows Lewis acids with varying characters in terms of both its ability to ease the anomerization and also to fix one of the anomers preferentially. The latter effect may also be operative to fix the kinetically formed $\alpha$ anomer in the Hf-promoted cases. More recently, we found that silicon behaves as an " $\alpha$-selective metal center", and in one of the rarer cases organosilane 36, in combination with $\mathrm{AgClO}_{4}$, leads to an excellent $\alpha$-selectivity $(\alpha / \beta=26 / 1)$.

5.2. Successful Route to Total Synthesis of Gilvocarcin M (ref. 10a). Scheme 4 shows our first synthesis of gilvocarcin M, which proved the L-series absolute stereochemistry, that had been long believed, is antipodal to the natural product.

The first step, the formation of aryl $C$-glycoside $35-\alpha$, is notable not only by its stereoselectivity (vide supra) but also by the regioselectivity that offers the basis for the following site-specific aryne generation. Thus, the phenol 35 was converted to the corresponding triflate 37, which was treated with $n-\mathrm{BuLi}$ in the presence of furan 22. The sugar-bearing benzyne, thus generated, underwent clean head-to-head cycloaddition with 22 to furnish the desired naphthalenetriol 38 with an L-fucofuranosyl moiety in high yield. Subsequent acylation, internal cyclization (ref. 11) gave the tetracycle, and final removal of four benzyl protecting groups gave unnatural gilvocarcin $\mathrm{M}$ in high yield.

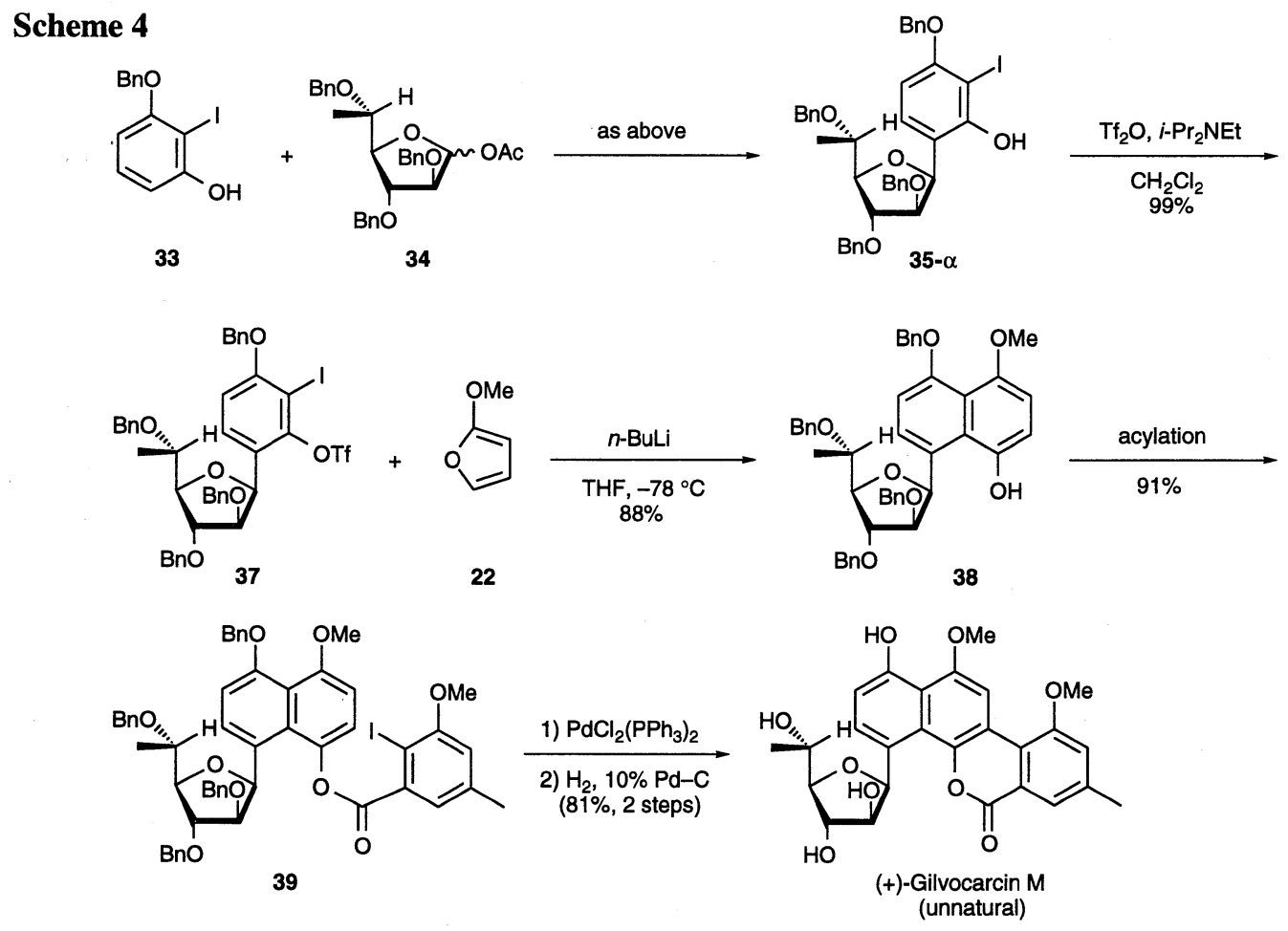


As the synthetic route is short and high-yielding (49\% overall yield for six steps), we immediately synthesized the natural enantiomer of $\mathbf{3 a}$, and essentially the same synthetic scheme was applied to the first total synthesis of gilvocarcin $\mathrm{V}$ possessing the vinyl group, essential to exhibiting biological activity (Scheme 5, ref. 10b). The naphthyl $C$-glycoside D-38 is common to the M-series synthesis, and the acylation was carried out with a benzoic acid $\mathbf{4 0}$ having a latent vinyl group. A triflate function, rather than an iodide (cf. Scheme 4), was used for the Pd-catalyzed internal biaryl bond formation, which proceeded reasonably well under carefully controlled conditions. Change of the protecting group from benzyl to acetyl, elaboration of the vinyl function followed by the liberation of four hydroxyl groups furnished the final compound $\mathbf{3 b}$.

\section{Scheme 5}<smiles>COCCc1cc(OC)c(O)c(C(=O)O)c1</smiles>

40

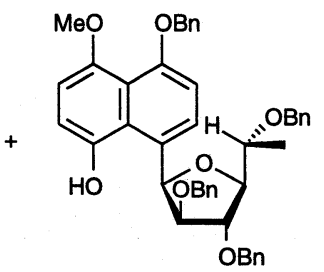

D-38
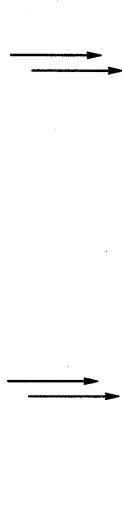

42

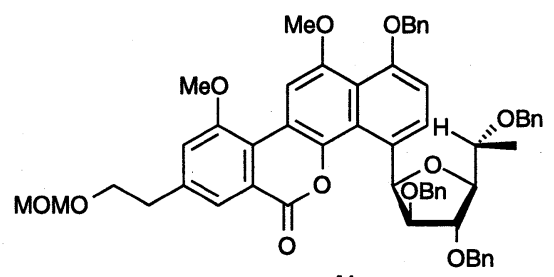

41

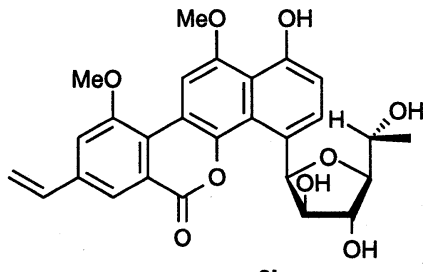

$\mathbf{3 b}$

\section{Conclusion}

In this account we have discussed the total synthesis of the gilvocarcin class antibiotics. More recently, we have been studying the total synthesis of a congener of this class, ravidomycin (12), having an amino sugar that renders the molecule more biochemically attractive and, at the same time, synthetically more challenging. We are currently enjoying development of the new synthetic methods which have evolved from solving the problems in this context (ref. 14). In addition, we have achieved the total synthesis of a closely related benzonaphthopyranone antibiotic, BE-12406A (43), having an $O$-glycoside structure rather than a $C$-glycoside (ref. 15).<smiles></smiles>

Ravidomycin (12)

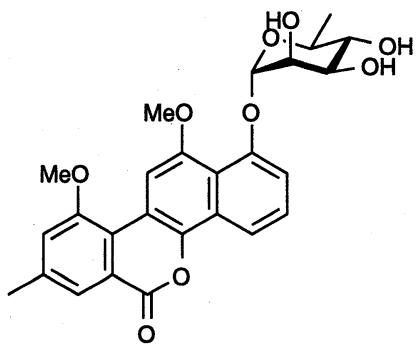

$B E-12406 A(43)$

Acknowledgments: The authors express sincere gratitude to the coworkers whose names appear in the references. 


\section{References}

(1) Reviews: (a) Hacksell, U.; Daves, G. D., Jr. Prog. Med. Chem. 1985, 22, 1. (b) Postema, M. H. D. Tetrahedron 1992, 48, 8545. (c) Suzuki, K.; Matsumoto, T. Recent Progress in the Chemical Synthesis of Antibiotics and Related Microbial Products, ed by G. Lukacs, Springer: Berlin, 1993, Vol. 2; p 353. (d) Suzuki, K. Pure Appl. Chem., 1994, 66, 2175.

(2) (a) Patten, A. D.; Nguyen, N. H.; Danishefsky, S. J. J. Org. Chem. 1988, 53, 1003. (b) Misra, R; Tritch H. R., III; Pandey, R. C. J. Antibiot. 1985, 38, 1280.

(3) Yamaguchi, M.; Okuma, T.; Horiguchi, A.; Ikeura, C.; Minami, T. J. Org. Chem. 1992, 57, 1647.

(4) Theriault, R. J.; Rasmussen, R. R.; Kohl, W. L.; Prokop, J. F.; Hutch, T. B.; Barlow, G. J. J. Antibiot. 1986, 39, 1509. Rasmussen, R. R.; Nuss, M. E.; Scherr, M. H.; Mueller, S. L.; McAlpine, J. B.; Mitscher, L. A. J. Antibiot. 1986, 39, 1515.

(5) (a) Matsumoto, T.; Katsuki, M.; Suzuki, K. Tetrahedron Lett. 1988, 29, 6935. (b) Matsumoto, T; Katsuki, M.; Jona, H.; Suzuki, K. Tetrahedron Lett. 1989, 30, 6185. (c) Matsumoto, T.; Hosoya, T.; Suzuki, K. Tetrahedron Lett. 1990, 31, 4629. (d) Matsumoto, T.; Hosoya, T.; Suzuki, K. Synlett 1991, 709. (e) Matsumoto, T; Katsuki, M.; Jona, H.; Suzuki, K. J. Am. Chem. Soc. 1991, 113, 6982.

(6) (a) Danishefsky, S. J.; Uang, B. J.; Quallich, G. J. Am. Chem. Soc. 1984, 106, 2453. Danishefsky, S. J.; Uang, B. J.; Quallich, G. J. Am. Chem. Soc. 1985, 107, 1285. (b) Tius, M. A.; Gu, X.; Gomez-Galeno, J. J. Am. Chem. Soc. 1990, 112, 8188. Tius, M. A.; GomezGaleno, J.; Gu, X.; Zaidi, J. H. J. Am. Chem. Soc. 1991, 113, 5775. (c) Bolitt, V.; Mioskowski, C.; Kollah, R. O.; Manna, S.; Rajapaksa, D.; Falck, J. R. J. Am. Chem. Soc. 1991, 113, 6320.

(7) Matsumoto, T.; Sohma, T.; Yamaguchi, H.; Kurata, S.; Suzuki, K. Synlett 1995, 263. Matsumoto, T.; Sohma, T.; Yamaguchi, H.; Kurata, S.; Suzuki, K. Tetrahedron 1995, 51, 7347.

(8) (a) Hatano, K; Higashide, E.; Shibata, M.; Kameda, Y.; Horii, S.; Mizuno, K. Agric. Biol. Chem. 1980, 44, 1157. (b) Horii, S.; Fukase, H.; Mizuta, E.; Hatano, K.; Mizuno, K. Chem. Pharm. Bull. 1980, 28, 3601. (c) Nakano, H.; Matsuda, Y.; Ito, K.; Ohkubo, S.; Morimoto, M.; Tomita, F. J. Antibiot. 1981, 34, 266. (d) Takahashi, K.; Yoshida, M. Tomita, F.; Shirahata, K. J. Antibiot. 1981, 34, 271. (e) Hirayama, N.; Takahashi, K.; Shirahata, K.; Ohashi, Y.; Sasada, Y. Bull. Chem. Soc. Jpn. 1981, 54, 1338. (f) Balitz, D. M.; O'Herron, F. A.; Bush, J.; Vyas, D. M.; Nettleton, D. E.; Grulich, R. E.; Bradner, W. T.; Doyle, T. W.; Arnold, E.; Clardy, J. J. Antibiot. 1981, 34, 1544. (g) Jain, T. C.; Simolike, G. C.; Jackman, L. M. Tetrahedron 1983, 39, 599.

(9) (a) Elespuru, R. K.; Gonda, S. K.; Science (Washington, D. C.) 1984, 223, 69. (b) McGee, L. R.; Misra, R. J. Am. Chem. Soc. 1990, 112, 2386.

(10) (a) Matsumoto, T; Hosoya, T.; Suzuki, K. J. Am. Chem. Soc. 1992, 114, 3568. (b) Hosoya, T.; Takashiro, E.; Matsumoto, T.; Suzuki, K. J. Am. Chem. Soc. 1994, 116, 1004.

(11) Deshpande, P. P.; Martin, O. R. Tetrahedron Lett. 1990, 31, 6313.

(12) Hoffmann, R. W. Dehydrobenzene and Cycloalkenes; Academic: New York, 1967.

(13) Matsumoto, T.; Hosoya, T.; Katsuki, M.; Suzuki, K. Tetrahedron Lett. 1991, 32, 6735. Matsumoto, T.; Sohma, T.; Yamaguchi, H.; Suzuki, K. Chem. Lett. 1995, 677. Also see ref. 7.

(14) Hosoya, T.; Ohashi, Y.; Matsumoto, T.; Suzuki, K. submitted for publication.

(15) Hosoya, T.; Takashiro, E.; Matsumoto, T.; Suzuki, K. Tetrahedron Lett. 1994, 35, 4591. Hosoya, T.; Takashiro, E.; Yamamoto, Y.; Matsumoto, T.; Suzuki, K. Heterocycles, in press.

(Recerved July 26, 1995) 